\title{
A “telinha particular”. Objetivo e funções da Web TV na Comunicação Organizacional: uma resenha dos estudos recentes
}

\author{
Pierfranco Malizia*
}

\section{Resumo}

Artigo sobre a Web TV na Comunicação organicaional. O objetivo é destacar, por meio de uma análise e uma reflexão sobre as principais investigações experimentais e insights teóricos, o estado da arte da Web TV como ela é hoje em seus aplicativos e nas próvaveis implicações futuras. As empresas precisam cada vez mais, para enfrentar com successo os desafios do mercado global e da vida organizacional, de utilizar com inteligência todas as experiências e as ferramentas oferecidas pela Comunicação em geral; Neste contexto, a Web TV pode ser mais uma oportunidade significativa: pelo menos isto parece ser o resultado deste trabalho.

Palavras chave: Comunicação Organizacional. Web TV. Marketing.

\section{A "little privaty TV". The goal and functions of Web TV in Organization Communication: a review of recnts studies}

\section{Abstract}

Paper about Web TV in Organizacion Counication. The goal is to show, using an analysis and a reflection about the main experimental and theoretical insights, the state of the art Web TV as it is today, with applications and future implications. To deal with success the global market challenges and organizational life, the companies need to use whit inteligence all experiences and tolls offered by Com-

\footnotetext{
* Professor doutor do Departamento de Ciencias Economicas e Politicas, Faculdade de Letras e Filosofia da Universidade LUMSA de Roma, Diretor do Curso de Pos-Graduação em Comunicação e do Centro de Pesquisa em Comunicação e Eventos da LUMSA, Universidade "La Sapienza" de Roma, Roma, Itália. Atua principalmente nas areas das trasformaçoes sociais, da produçao cultural e da Comunicação. Publicou, entre outros, os livros "Comunic-a-zioni" (Milano, 2006), "Configurazioni” (Milano, 2007), "Al plurale” (Milano, 2008),"Contesti e dinamiche" (Soveria Mannelli, 2011) e"Uncertain outlines" (Saarbrücken, 2012).E-mail: pfmalizia@yahoo.it
} 
munication in general. In this context, the Web TV can be one more significant opportunity: at least this seems to be the result of this research.

Keywords: Organization Communication. Web TV. Marketing.

\section{Una "pequeña TV privada". Funciones y objetivos de la Web TV en Comunicación Organizacional: una revisión de estudios recientes}

\section{Resumen}

Artículo sobre la Web TV en Comunicación Organicaional. El objetivo es destacar, a través del análisis y de la reflexión sobre las principales conclusiones teóricas y experimentales, la situacione actual de la Web TV y las implicaciones futuras probables. Para hacer frente en el mercado global con successo, las empresas necesitan cada vez más usar con inteligencia todas las experiencias y las herramientas que ofrece la la Comunicación en general. En este contexto, la Web TV puede ser la oportunidad más significativa: al menos este parece ser el resultado de este trabajo.

Palabras clave: Comunicación Organicaional.Web TV. Marketing.

\section{Introdução}

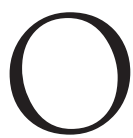

s sistemas sociais em geral e as organizações formais (Malizia, 2005) em particular vivem e desenvolvem-se construindo tanto processos de Comunicação, de significação e de aprendizagem, como de divulgação e de partilha dos mesmos nas diferentes redes de relação que os constituem. Este trabalho é dedicado a tais questões e conteúdos, "navegando" não só apesar de principalmente - através das possíveis aplicações e dos desenvolvimentos da Web TV introduzidos quer pelas NTICs na vida organizacional, quer pelo implacável impacto da information technology com o seu carácter de polimorfa aplicabilidade. Tais circunstâncias mudaram substancialmente o modus vivendi das relativas organizações, produzindo de fato uma real "revolução semântica" quer na leitura e na investigação da Comunicação Empresarial, quer na "vida quotidiana" das empresas. Neste trabalho, vamos ter também em forte consideração a importância dos fatores "soft" quer para a análise das dinâmicas organizacionais, quer para as práticas estratégico-gerenciais; quanto, por fim, para 
a produção de valor no âmbito da Comunicação Institucional e de Marketing. Por outras palavras, hoje em dia estamos a assistir ao desenvolvimento de um novo "valor acrescentado" para a empresa em termos de:

- maior circulação e divulgação das informações, pedidos, competências, valores, identidades e cultura da organização através das NTICs;

- maior e mais intenso envolvimento quer dos membros da organização, quer dos clientes/usuários;

- suportes tecnológicos para a criação de best practices;

- desenvolvimento da experiência organizacional por meio de uma maior integração com os diferentes stakeholders.

Durante esta última década, destacou-se em particular o papel e a funcionalidade da Web TV na Comunicação Empresarial: por esta razão, consideramos útil fornecer ao leitor uma resenha dos estudos mais recentes sobre esta temática. Finalmente devemos lembrar que, como já foi bem confirmado (Colletti-Dubini-Prestinari, 2007), o atual e rápido desenvolvimento dos serviços de business television é o produto de dois grandes processos evolutivos que na última década interessaram o sistema dos média e, em particular, o universo audiovisual. Hoje em dia, estes processos, que se originaram em dois âmbitos bem distintos, resultam cada vez mais contíguos e determinam um jogo cruzado de efeitos que alteram a natureza do relativo conceito de televisão tal como foi entendido até agora. Estes dois processos criam hoje as condições para o desenvolvimento de aplicações televisivas destinadas também a ambientes de business.

Os dois processos mencionados são: por um lado, o abatimento dos custos de produção e distribuição dos serviços televisivos com o subsequente desenvolvimento da televisão digital multi-canal e, por outro, a evolução de um sentido plenamente audiovisual dos serviços multimédia da rede.

Esta dupla evolução torna-se até mais significativa do que um processo amplamente mais interessante, ou seja o da convergência e da hibridização entre três grandes "famílias" de sistemas de Comunicação, respetivamente destinados ao tratamento dos 
documentos, à Comunicação interpessoal e à publicação de conteúdos. Estes sistemas, que anteriormente eram totalmente distintos, baseiam-se hoje nas mesmas estruturas técnicas. Isto significa que com a mesma máquina, com a qual comunicamos, podemos também administrar os documentos e consumir conteúdos editoriais. Desta maneira caem algumas barreiras tradicionais entre os diferentes universos do consumo e do tratamento dos conteúdos.

A meta deste trabalho é exatamente aquela de destacar, por meio de uma análise e uma reflexão sobre as principais investigações experimentais e insights teóricos, o estado da arte da Web TV como ela é hoje em seus aplicativos e nas próvaveis implicações futuras.

\section{A “TV empresarial”: generalidades}

Pesquisa recente (INCLETOLLI, 2011) define e desenvolve claramente as principais caraterísticas/propriedades estruturais da Web TV, o canal realizado e produzido pela empresa para gerenciar e transmitir conteúdos audiovisuais na Web: trata-se de um instrumento a que podemos aceder por meio de qualquer browser/ferramenta capaz de veicular format/pílulas de Corporate TV, realizados tendo em conta o público empresarial e destinados, entre outros assuntos, à promoção, comercialização, formação e informação.

a) Em termos de objetivos, a Web TV apresenta objetivos primários, relacionados principalmente com as necessidades da empresa de informar e formar. Podemos identificar também objetivos secundários, como o reforço da identidade/cultura empresarial e o envolvimento dos funcionários, em particular - como mencionaremos mais à frente na parte dedicada às caraterísticas - por meio de qualquer modalidade de interação entre o usuário e o format televisivo.

b) Em termos de caraterísticas, a Web TV destaca-se pelo facto de permitir a adoção de um código comunicativo que ativa diferentes sentidos no usuário (audição e visão), permitindo assim a transmissão de informações - até 
complexas - por meio de um format facilmente utilizável e, sendo um média de prolongado e generalizado uso habitual no âmbito extra-laboral, permite a rápida e fácil receção das mesmas informações por parte do usuário. Conforme as tecnologias e as políticas de transmissão adotadas pela empesa, este instrumento permite também combinar a tempestividade da informação (streaming live) com a flexibilidade na fruição da informação (streaming on demand). A tecnologia streaming faz com que a transmissão de dados, relativos à produção televisiva empresarial, não seja muito invasiva: a solução live permite enviar mensagens em direto a todos os usuários do instrumento, enfatizando as caraterísticas de média tempestividade da Web TV. Além disso, em função da tecnologia adotada, o instrumento permite definir os esquemas de interação do usuário: da participação direta na transmissão (por exemplo, enviando perguntas a uma determinada conta e-mail), à possibilidade de baixar, na mesma área de transmissão do vídeo, o material de acompanhamento da transmissão visualizada.

c) Em termos de conteúdos, os conteúdos da Web TV, conhecidos também como programas, são apresentados numa grelha (instrumento dirigido aos usuários que evidencia o título, a tipologia, a hora do início do programa e qualquer informação acessória). São confecionados dentro de um format (sistema de regras que determinam a estrutura do programa adotado em programas exclusivos ou em séries de transmissões). Por meio da Web TV veiculam-se conteúdos informativos (como, por exemplo, telejornais empresariais, aprofundamentos sobre comunicados de imprensa), institucionais (entrevistas ao management, crônicas de eventos cruciais da empresa), formativos (formats baseados em específicas vertentes formativas, frequentemente comportamentais), comerciais (format de aprofundamento sobre serviços/produtos, format sobre temáticas técnico-normativas com impactos na rede comercial etc.), conteúdos relacionados com os 
recursos humanos (format dedicados às relações entre colegas, às iniciativas de agregação realizadas pelas associações de funcionários, às vantagens da vida empresarial, aos aprofundamentos sobre questões de segurança, de administração e de assistência social).

d) Em termos de periodicidade, a periodicidade da Web TV depende das escolhas relativas às grelhas ou à produção das clip on demand.

e) Em termos de target, o target da Web TV é representado pela inteira população empresarial, pelos stakeholders e pelos usuários/clientes. Quando for possível, a tecnologia e a iniciativa - enquanto resultado das escolhas da Comunicação interna - permitem identificar até targets secundários (resultado da segmentação da população empresarial, como por exemplo escolher a identificação dos usuários da rede comercial e/ou de segmentos individuais de business), de modo a estruturar conteúdos/formats acessíveis e destinados apenas para os clusters empresariais identificados.

f) Em termos de realização, a realização dum projeto de Web TV prevê várias soluções de implantação, que vão desde o âmbito editorial até aquele tecnológico e produtivo. De qualquer forma, de acordo com a amplitude e complexidade do projeto suposto, aconselhamos adotar a solução da total atribuição externa da realização dos conteúdos do produto da Web TV.

g) Em termos de custos, é difícil quantificar o impacto da Web TV no orçamento. O investimento é significativamente diferente, de acordo com o perfil do projeto perseguido, com o tipo de tecnologia de transmissão escolhido e com o relativo modo de produção dos format. É oportuno ter em consideração que o nível tecnológico atual permite a realização de format até a baixo custo.

h) Em termos de projetualidade, é recomendável que um projeto de Web TV inclua algumas competências específicas como: de Comunicação (por exemplo, para a criação de um format e de uma grelha); técnicas (por exemplo em relação ao mundo da "produção", realização, iluminação, 
filmagem etc.); e tecnológicas (por exemplo em relação às temáticas de transmissão e de "pós-produção").

i) Finalmente, em termos de medição da eficácia, a Web TV oferece a possibilidade de efetuar diferentes formas de pesquisas como: 1) Quantitativas - a transmissão na Internet permite traçar diferente dimensões (por exemplo, número de usuários por programa, quantas visitas conseguiu um específico programa formativo, número de usuários por horário, tempo de visualização por cada programa etc.); 2) Qualitativas - por meio da implementação de canais de escuta específicos (criação de uma conta e-mail da redação da TV dedicada à receção de sugestões, predisposição de inquéritos por meio da intranet, distribuição de questionários por correio eletrónico, ativações de chats dedicadas a format específicos etc.), subsiste a possibilidade de investigar aspetos "redatoriais" (receção de mensagens info-formativos e/ou aprovação de um format, de uma maneira específica de condução etc.); 3) a análise dos feedbacks, obtida por meio o cruzamento dos dados qualitativos com os quantitativos, é fundamental para orientar os desenvolvimentos da Web TV - permitindo também intervenções corretivas em fase de processamento - e desempenha o papel de tornassol para verificar o cumprimento dos objetivos identificados.

\section{NTICs e Web TV na Comunicação Organizacional}

Maimone (2010) identifica claramente as principais estruturas e temáticas relacionadas com a Comunicação Corporativa em geral e com a natureza específica da Web TV que, neste contexto, assumiu há vários anos uma importância muito especial; vejamos agora os principais temas desenvolvidos:

\section{I. Os portais}

Atualmente podemos identificar três principais categorias de websites: 1) o website informativo, geralmente dedicado ao B2B das pequenas e médias empresas, com nível muito baixo de interação; 
2) o website multimedial, geralmente dedicado ao B2C das médias e grandes empresas, com nível médio de interação; e 3) as redes sociais altamente interativas, com máximo nível de interação.

Não se trata, obviamente, de uma categorização exaustiva, dado que existem inúmeros tipos de websites que fazem parte dos níveis intermédios desta tripartição: mas é útil para termos uma ideia do nível de interação permitida pelos diferentes portais da Web que hoje encontramos na rede.

Os portais Web que abrangem as três categorias acima mencionadas são aqueles caraterizados pelo desenvolvimento de um fluxo de Comunicação integrada - considerada como um entrelaçamento de fluxos de informação, canais média e instrumentos interativos a vários níveis, do audiovisual aos jogos online - quer para desenvolver a imagem da empresa e do relativo brand, quer para a tornar acessível aos grupos target de referência; podemos definir o portal como um produto editorial online que desempenha para os usuários a função de ponto privilegiado de acesso à Web, fornecendo-lhes recursos de informação, serviços de Comunicação pessoal e instrumentos com os quais localizar e alcançar os conteúdos e os serviços online de que normalmente precisam.

Existem geralmente duas tipologias de portais:

- os portais horizontais, ou portais generalistas, não especializados, que se dirigem a usuários indiferenciados;

- os portais verticais, conhecidos também como portais temáticos, instrumentos de nicho que oferecem, pelo contrário, aplicações e serviços dedicados a específicos domínios temáticos ou dirigidos a específicos grupos ou comunidades.

Os portais empresariais ou Corporate Portal representam, segundo os autores, uma evolução natural da Intranet e da Extranet em relação ao modelo portal; por um lado, têm caraterísticas em comum com os portais verticais, por outro diferenciam-se quer pela estrutura, quer pelas funções.

Trata-se precisamente de websites empresariais que incluem todas as informações necessárias para o funcionamento da empresa, quer dizer os fluxos informativos e de Comunicação dirigidos para o interior (colaboradores e membros da empresa) e para o exterior (clientes e fornecedores). Os portais empresariais complexos po- 
dem ser utilizados como Application Service Provider: isto significa colocar à disposição instrumentos e aplicações que interajam com o sistema informativo empresarial e fruir de serviços e-commerce de tipologia B2C (business to consumer) e B2B (business to business), destinado então a outras organizações ou aos fornecedores. Este tipo de Comunicação nasce portanto do uso coordenado de vários instrumentos à disposição para a Web e de diferentes média disponíveis para as numerosas tipologias de Comunicação Empresarial, com um efeito global de redundância da mensagem, a ser tanto dirigida para diferentes tipologias de utilizadores, como enviada por meio de modalidades diferentes conforme os corolários da mensagem a serem transmitidos. Além disso, um portal Web que desenvolve fluxos de Comunicação Integrada usa todos os instrumentos ao seu dispor para atualizar as mensagens transmitidas, conforme as respostas dos usuários ou as mudanças que ocorrem na relativa mensagem. A Comunicação Integrada interessa principalmente os efeitos de três endereçamentos da Comunicação Empresarial: o institucional, o de marketing e, last but not least, a Comunicação Interna. Isto significa influenciar, antes de mais nada, a atitude e a aproximação dos grupos target relativamente ao brand, fomentando a notoriedade da marca e desenvolvendo a visibilidade da empresa, a sua posição e qualificação; sobre marketing, isto significa agir determinando o subsequente comportamento do consumidor por meio da Comunicação quer direta (e-mail, newsletter, contatos telefónicos, ofertas personalizadas etc.), quer indireta (broadcasting televisivo, radiofónico, informático, RSS etc.). Quanto à Comunicação interna, podemos afirmar que o seu objetivo consiste em estimular a motivação do pessoal interno e a colaboração de cada um no que respeita temáticas e projetos de interesse comum.

O desenvolvimento de uma Comunicação Integrada permite, portanto, canalizar os diferentes fluxos de mensagens, coordenando-as numa única ação complexa que visa o desenvolvimento da reputação empresarial, devida quer ao produto oferecido e à atividade promocional à qual está sujeito, quer à confiança que a empresa será capaz de obter por parte do target em relação ao seu trabalho em geral, resultado da união entre atividades de back e de front office. 
Naturalmente, para obter os melhores resultados, é necessário um planejamento detalhado e estruturado da atividade de Comunicação que evidencie os pontos chave por meio dos quais se pode estruturar o processo de Comunicação, ou seja, instrumentos de Comunicação e canais média disponíveis. Os primeiros abrangem todas as maneiras que o emissor pode utilizar para enviar a própria mensagem institucional e promocional relativa ao produto, inclusive meios tradicionais de Comunicação (direct mailing, newsletter, brochuras e catálogos, promoções dirigidas a clientes ou a consumidores finais), participação em eventos, exposições, feiras e organização de conferências para publicitar a empresa e o relativo produto. Além disso, é possível usar uma grande variedade de canais mediáticos por meio dos quais a empresa pode enviar a própria mensagem: dos médias tradicionais às novas fronteiras telemáticas oferecidas pela Web, aos ambient-media que incluem cartazes, circuitos de afixações metropolitanas e publicidades aplicadas em meios de transporte público.

\subsection{A Intranet}

A Intranet, como sabemos, é uma rede empresarial privada de acesso restrito que utiliza as tecnologias web based. Trata-se portanto duma rede telemática fechada, protegida por um firewall, ou seja um sistema de proteção contra acessos não autorizados e que usa diferentes tecnologias integradas entre elas para permitir:

- a partilha de informações, documentos e conteúdos (textuais, áudio, vídeo, multimédia);

- a gestão de procedimentos e da burocracia;

- o trabalho à distância (sistemas de workflow, groupware e project-work);

- a tomada de decisão (decision support system);

- o e-learning e a aprendizagem colaborativa;

- a Comunicação síncrona e assíncrona e a produção colaborativa de conteúdos (nos fóruns, wiki, blogues etc.);

- o knowledge management (repository, sistemas de data mining e retrieving, motores de busca inteligentes, sistemas de knowledge intelligence etc.);

- o desenvolvimento de social network internos. 


\subsection{A Web TV empresarial}

A Web TV empresarial é uma Corporate TV difundida por meio da rede. A escolha do instrumento nunca é irrelevante em relação às características e aos efeitos produzidos. De fato, a Web TV permite integrar as funcionalidades da Corporate TV tradicional - baseada no broadcasting (difusão etc.) - com as especificidades dos instrumentos web based.

Em particular, a Web TV carateriza-se por: interatividade, flexibilidade, interoperabilidade. Pode-se gerir de maneira central (broadcasting) ou participativa (redação difundida): portanto, permite divulgar conteúdos quer em tempo real, quer em diferido (também on demand). Como a Web TV permite a publicação de conteúdos provenientes de baixo, aproxima-se das lógicas da Web 2.0. Por esta razão, nos últimos anos verificou-se a difusão da Web Corporate TV nas empresas italianas, dirigida a target tanto externos (stakeholders, fornecedores, clientes etc.), quanto internos.

\section{NTICs e Web TV para a Comunicação de marketing}

\section{I As NTICs, as empresas, o mercado}

Como a empresa deve enfrentar (Malizia, 2005) uma concorrência cada vez maior e como deve sobreviver e desenvolver-se num contexto cada vez mais globalizado, para ser competitiva necessita de reduzir os custos e os tempos de Comunicação, de promoção, de venda e, em geral, de transferência de dados e informações. A Internet, como instrumento de Comunicação rápido e de baixo custo, é uma solução ideal para satisfazer todas estas necessidades. As empresas, portanto, utilizam cada vez mais a Internet para uma série de necessidades diferentes, como por exemplo:

- Comunicação global: graças à Internet, a empresa pode comunicar cada vez mais veloz e economicamente com o mercado, com os próprios fornecedores e clientes e, dentro da mesma estrutura, com os próprios funcionários.

- Marketing direto: graças à Internet, a empresa pode lançar campanhas publicitárias, efetuar pesquisas de mercado, monitorar a concorrência e buscar novas oportunidades de business. 
- Venda: graças à Internet, a empresa pode efetuar a venda direta dos próprios produtos/serviços e a distribuição direta dos bens digitalizáveis. Tudo isto é possível por meio da Web, se a empresa adotar eficazes sistemas de segurança para a transferência de pagamentos e transações.

- Transferência de dados e informações: a Internet permite transferir mais facilmente informações e dados, dentro do próprio sistema, entre as empresas e entre as empresas e os seus funcionários. Pode-se realizar tudo isto por meio da criação de hiperligações "seguras", por exemplo, por meio da criação de redes Intranet ou Extranet.

- Redução dos custos: é até possível, em geral, reduzir os custos de Comunicação. $\mathrm{O}$ uso da rede pode reduzir os custos do trabalho (com o teletrabalho e a atualização), do Marketing, da Publicidade, da venda (com o comércio eletrónico), da distribuição e da pesquisa de informações estratégicas.

- Redução dos tempos: a Internet permite, em geral, reduzir os tempos da Comunicação para a entrega de bens imateriais e de serviços, no processo de produção e na formação a distância (distance learning); todas estas necessidades podem ser reavaliadas desde três diferentes pontos de vista: 1) um ponto de vista externo, dirigido ao mercado global; 2) um ponto de vista interno dirigido à empresa; e 3) um ponto de vista inter-empresarial relativo à relação entre as empresas.

A Internet é a rede das redes que permite portanto à empresa, de qualquer dimensão, comunicar com o exterior. Ela fornece à empresa novos instrumentos, tanto no campo do Marketing como no campo comercial, para atingir o maior número possível de clientes no mundo e para operar assim desde uma perspetiva global.

Vejamos agora, brevemente, as principais áreas de aplicação: em termos de marketing, podemos delinear pelo menos cinco diferentes atitudes das empresas relativamente ao uso da Internet:

1. Acesso: neste caso a empresa liga-se à Internet para encontrar informações sobre o próprio mercado e sobre a concorrência, sem entrar diretamente na Rede e portanto sem comunicar diretamente com o exterior. 
2. Presença: neste caso, a empresa quer que a marca, e também parte do mostruário, sejam visíveis na Rede de maneira a não prejudicar a própria imagem em relação os concorrentes.

3. Publicidade: neste caso a empresa quer associar mais estreitamente a própria imagem àquela da rede, utilizando a Web como um instrumento de diálogo com os clientes tanto tradicionais como novos, aos quais apresenta os novos produtos e as novidades. Muitas vezes a empresa deseja que o cliente possa usar a Rede para comunicar com a mesma firma, fornecendo os próprios dados e fazendo perguntas.

4. Venda: as empresas podem apresentar os próprios catálogos dos produtos e gerenciar pedidos e pagamentos diretamente na Internet com a máxima segurança na gestão das transações. Alguns setores produtivos, como, por exemplo, a informática e a eletrónica de consumo (computadores, hi-fi etc.), são particularmente adequados para a comercialização direta na Rede.

5. Serviço: uma minoria de empresas, finalmente, pode usar a Internet também para a distribuição direta dos próprios produtos (geralmente software ou produtos editoriais). Mesmo neste caso é oportuna a máxima segurança no processamento das transações e na transferência dos ficheiros-produto.

\subsection{A Web TV como instrumento de criação de valor}

Como já foi apropriadamente evidenciado (Colletti-Prestinari-Dubini, 2007), para as empresas que na última década começaram a usar intensamente a Web com o objetivo de criar uma relação direta com o próprio público, nasce concretamente a oportunidade de utilizar o poder emocional do vídeo e da televisão para enriquecer uma relação que, em alguns casos, já resulta forte.

Sendo uma propriedade típica da Web, também para os vídeos existe a possibilidade de definir modelos editoriais extremamente diversificados para comunicar. Isto é sem dúdiva uma grande oportunidade, mas é ao mesmo tempo um problema de seleção e de complexidade a administrar. 
Sem dúvida, é possível produzir e "transmitir" televisão diretamente ao público com barreiras de acesso essencialmente inexistentes e a custos muito baixos; desta maneira, as restrições editoriais que a televisão tradicional impunha à presença da Comunicação Empresarial deixam obviamente de existir. Além disso, é igualmente inegável que não é fácil nem imediato elaborar modelos de serviço que possam satisfazer as necessidades de um público que tem à disposição uma escolha cada vez mais vasta.

De fato, parece que a Web TV repropõe temas similares aos propostos até hoje pela Web: isto significa aproveitar uma oportunidade que é extremamente interessante, mas ao mesmo complexa de gerir por ser um meio extremamente aberto e flexível.

Sendo a business TV um interessante instrumento interno, o potencial relacionado com o seu uso externo é certamente ainda mais interessante, como implica a possibilidade do uso direto e livre da TV (quer dizer, aquela nova na lógica da Web) por parte das empresas como alavanca competitiva.

Além da explosão do vídeo na Rede, surpreende também a propagação de outro fenômeno, cada vez mais analisado sobretudo por parte dos escritórios de Marketing das empresas de médias e grandes dimensões: estamos a falar das communities empresariais, que já não se encontram nas Redes fechadas dos portais Intranet. Agora estas communities desempenham também um papel de mostrador para o consumidor externo, conseguindo resultados mensuráveis não só em termos de acesso, mas também em termos de qualidade da oferta recebida, ou seja em termos de proximidade ao cliente. Esta situação foi considerada importante só nos últimos tempos, especialmente depois do surgimento das produções em série da business TV. A intenção é impressionar, mas de forma consciente.

Longe das lantejoulas e das paillettes dos efeitos de pós- produção da Alta Definição, a empresa também considera com interesse o vídeo pela sua capacidade de contar histórias.

Misturando corajosamente os ingredientes acima mencionados - ou seja a TV na era da Web 2.0, as knowledge communities e a atenção ao cliente - surge então a última tendência no âmbito do vídeo empresarial. Trata-se, portanto, de um fenómeno que adquire o nome de brand TV, meio que permite encontrar uma 
receita de forte eficácia para diferentes níveis de interação com o consumidor usuário final.

Para desenvolver ainda mais o nosso discurso, partamos agora do pressuposto (Nysveen-Thornbjorsen-Pedersen, 2004a e 2004b) de que a interatividade e a personalização são as duas caraterísticas mais importantes de diferenciação entre a Web TV e o canal televisivo tradicional. Estamos portanto no território da chamada "convergência multimédia", que envolve os seguintes elementos:

a) Interatividade: é preciso lembrar, a este propósito, um elemento distintivo entre a interatividade humana (indivíduo-interatividade) - ou seja a Comunicação por meio de um meio - e a interatividade por meio da máquina (acesso interativo a um conteúdo de hipermédia). O conceito de homem-interação refere-se àquela funcionalidade que permite comunicar, independentemente da distância e do tempo, tanto aos indivíduos como às organizações. Desde este ponto de vista, a Web TV pode tirar proveito, por exemplo, implementando um serviço que permita aos usuários fazer comentários ou perguntas às pessoas que participam num programa de televisão. Além disso, a Web TV pode oferecer chat rooms e message boards, permitindo aos usuários - bem como às pessoas que trabalham para um determinado brand/canal - expressar as próprias opiniões sobre um determinado programa de TV e discutir com outros usuários sobre este último ou sobre temas relacionados. A Web TV permite ver a cada consumidor um programa de televisão no lugar e no tempo mais apropriados às específicas necessidades. Outra possibilidade consiste em dividir o ecrã do próprio computador em várias janelas, dando a possibilidade ao usuário de ver mais de um programa ao mesmo tempo.

b) Personalização: a Personalização representa a capacidade de adaptar a informação e os conteúdos para satisfazer melhor as específicas necessidades e as exigências de cada consumidor. Tais ajustes são geralmente possíveis graças a um user ID e a um perfil. A televisão na Web permite quer um direcionamento individual, quer uma 
aproximação personalizada em relação aos grupos de usuários. A personalização deriva da interação. Os websites personalizados são espaços dinâmicos, nos quais cada usuário pode subscrever determinados serviços de acordo com o próprio perfil individual. Assim como na Web, a interatividade amplia a vantagem competitiva das emissoras, dado que permite um acesso a uma informação que resulta personalizada e relevante para uma audência específica. A interatividade e a personalização são duas úteis estratégias de Marketing para atingir esta finalidade. Por meio dos fluxos interativos e personalizados de informação entre o brand e o consumidor, que ocorrem através da Web TV, os consumidores recolhem material importante que contribui para a formação das opiniões sobre o brand e, ao longo do tempo, de um sentimento de identificação com a mesma marca. A conexão que se estabelece entre o brand e o conceito que um indivíduo tem de si próprio ajuda a formar e a mudar as atitudes em relação ao brand: desta maneira, as dimensões da relação "consumidor-brand" reforçam-se progressivamente.

c) Convergência: a interatividade da Web, juntamente com os formast televisivos, gera portanto uma convergência entre a TV tradicional e a Web. Esta convergência de canal faz com que os consumidores tenham a oportunidade de aproveitar do uso quer da Web, quer da televisão por meio de um único canal, que é portanto aquele da Web TV. Existem, aliás, vários aspetos que separam a TV tradicional da Web TV. Parece até razoável supor que a Web TV servirá para complementar - e não substituir - a TV tradicional. Por um lado, isto quer dizer que as pessoas continuarão a usar a TV tradicional e a ver os programas tradicionais; por outro, a TV e a Web TV reforçarão reciprocamente as próprias posições como canais de marketing e de distribuição.

Para estudar como as integrações dos canais da Web TV podem influenciar a relação "brand-consumidor", vamos ter como 
ponto de referência o modelo relacional de investimento; podemos definir a relação "brand-consumidor" como um vínculo de longo prazo - dinâmico e cheio de emoção entre um consumidor e um brand - que inclui algum tipo de interdependência, história partilhada e obrigações de tipologia instrumental ou sócio-emocional.

O modelo inclui construções como a satisfação, a qualidade das alternativas, os investimentos na relação tanto direta como indireta e o empenho. Todavia, nós adotamos uma versão simplificada deste modelo: apesar disso, colocamo-lo no centro do Marketing, do branding e das associações de marca. Se aplicarmos a este propósito as teorias relacionais (derivadas da psicologia social para explicar o consumo dos média e a relação brand-consumidor), será provavelmente necessário alterar ou incluir novas variáveis para compreender melhor este particular contexto. O conceito de associação de marca (brand association) é aqui considerado como uma variável pela sua importância em indicar a força da relação com o brand (Keller, 1998). Mais especificamente, emprega-se a variável associação como responsável pela criação da singularidade do brand na mente dos consumidores.

As associações de marca foram concetualizadas como nós de informação relacionados com a memória do brand, que contém o significado pessoal que o consumidor tem acerca de um determinado brand. Supõe-se que a especificidade e a força das associações de marca representam alguns dos indicadores mais significativos da relação "consumidor-brand". Um dos conceitos centrais do Marketing moderno é exatamente a satisfação com uma marca, que se verifica de fato por meio da influência positiva que exerce na perceção do consumidor e nos seus comportamentos em relação ao brand de referência.

O nível de satisfação com o brand está relacionado com a soma das emoções do consumidor, tanto positivas como negativas, relativamente à mesma marca. Este princípio é frequentemente definido como a expectativa da performance em relação ao brand, princípio relacionado com as performances efetivamente recebidas e com a confirmação ou desconfirmação das expectativas em relação ao mesmo brand. Portanto, a satisfação em relação a um determinado brand pode ser influenciada tanto pelo desenvolvimento do produto como pelo controle. 
As quatro dimensões do brand aqui discutidas referem-se todas à perceção que o consumidor tem relativamente ao brand ou à relação que ele estabelece com o mesmo. De acordo com as teorias sobre o comportamento dos consumidores, bem como as teorias sobre a relação, a perceção relativa a um determinado brand ou produto tem um impacto direto sobre o comportamento do consumidor.

Finalmente, será útil especificar algumas hipóteses de desenvolvimento funcional da Web TV em relação ao Marketing. Os canais múltiplos deveriam ser utilizados na Comunicação de Marketing para criar associações de marca positivas. Isto é devido ao princípio da variabilidade da codificação, segundo o qual a informação apresentada em diversos contextos faz com que esta última seja codificada de maneiras ligeiramente diferentes. Isto implica que as empresas possam provavelmente obter um benefício graças à variedade dos canais e dos format na tentativa de comunicar com os próprios consumidores. Esta situação vai oferecer múltiplos sinais para recuperar a informação, de modo a aumentar a performance da memória. Finalmente, esta situação determinará na memória uma associação da marca mais forte.

Além disso, os serviços interativos e personalizados presentes na Web TV têm o potencial de criar nexos entre os conceitos que cada consumidor tem tanto de si próprio como do brand. Quando os consumidores relacionam as associações de marca com o conceito de si próprios, as associações de marca tornam-se mais salientes, relevantes e únicas. A este propósito, é portanto possível delinear as seguintes hipóteses:

1. O consumo por parte dos consumidores dos canais integrados da Web TV está positivamente relacionado com a singularidade da associação de marca. De acordo com o paradigma de confirmação/desconfirmação, o aumento da perceção que o consumidor tem relativamente às performances do brand vai aumentar consequentemente a brand satisfaction. Além disso, os brands que satisfazem as expectativas dos consumidores serão avaliados positivamente. A interatividade e a personalização são algumas das qualidades exclusivas que caraterizam a Web TV em comparação com a TV tradicional. Po meio da interatividade e da 
personalização, o brand poderá refletir a opinião pessoal que o consumidor tem de si próprio, os seus valores e as suas preferências. Um nexo deste género entre o brand e o conceito de si próprio vai aumentar a avaliação que o consumidor fará relativamente ao brand, dado que o consumidor guarda esta associação positiva em relação a si próprio. Além disso, quando o brand atua de acordo com o perfil personalizado do consumidor, as próprias performances corresponderão, portanto, às expectativas e a tudo o que tem valor para o consumidor. Consequentemente, tanto o aumento da perceção das performances de um brand como o cumprimento das expectativas do consumidor contribuem para a satisfação em relação ao brand (brand satisfaction).

2. O consumo dos canais integrados da WebTV está positivamente relacionado com a brand satisfaction. Os investimentos na relação direta, baseados em componentes de tipo econômico e psicológico, representam importantes laços entre o consumidor e o brand. Todavia, existem diferentes modelos de rendimento para os sites da Web TV. Um dos mais amplamente utilizados é aquele de pré-pago com a subscrição baseada no tempo de utilização (por exemplo uma semana ou seis meses), mas isto implica um risco: o consumidor pode perder parte do dinheiro, dado que a subscrição pode caducar antes do período de interesse. Os serviços da Web TV incluem muitas vezes elementos de personalização. Se o usuário quiser passar ao serviço Web TV de uma marca concorrente ou alternativa, ele está obrigado a personalizar de novo o próprio perfil. Esta mudança implica que o usuário aprenda a utilizar uma nova interface com novas funcionalidades. Por conseguinte, o tempo decorrido para personalizar e utilizar a nova interface vai mudar a perceção acerca dos investimentos diretos em relação ao brand. Consequentemente, gera-se uma relação positiva entre o uso da Web TV por parte do consumidor e os investimentos na relação direta. 
3. O uso por parte dos usuários dos canais integrados da WebTV é positivamente relacionado com os investimentos na relação direta. Os investimentos na relação indireta referem-se a recursos externos, como: os amigos em comum, a identidade pessoal e a partilha do mesmo objeto. Os serviços da Web TV podem ser personalizados de acordo com as preferências de cada usuário. Os usuários podem escolher os programas, as funções e os serviços que satisfaçam os próprios específicos valores. Um cliente, por exemplo, pode subscrever um determinado canal desportivo, dado que o futebol é um aspeto importante da própria identidade, ou um cliente pode subscrever um programa específico porque tem uma amiga/um amigo em comum com o apresentador do programa. Os programas e os serviços não apreciados pelos usuários não aparecerão portanto no site Web TV personalizado. Por conseguinte, os consumidores terão provavelmente a perceção de que os serviços da empresa emitente oferecem material autoreferencial que reflete os próprios valores pessoais, a própria imagem e a a própria identidade. Introduzindo específicas chat-rooms relacionadas com o relativo programa, ou lendo e escrevendo mensagens e comentários relacionados com o programa, é também possível para os usuários expressar as próprias opiniões sobre o mesmo programa.

\section{Referências}

CODEIRO J.; HAMMANDI, S. (orgs.). Web information systems and technologies. Heidelberg: Springer, 2009.

COLLETTI G.; DUBINI, P.; PRESTINARI P. Business TV. Milano: Università Bocconi, 2007.

HA, L.; GANAHAL R. (orgs.). Business models of an emerging global medium. Mahwah: Erlbaun, 2007.

INCLETOLLI, M.(ed.). La comunicazione interna delle banche italiane. Roma: ABI, 2011. 
LAVEN, P. Predicting the future of broadcasting. EBU Tecnical Rewiew, n.2, 1998. p.26-36.

MAIMONE, F. La comunicazione organizzativa. Milano: Franco Angeli, 2010.

MALIZIA, P. Comunicazione e organizzazione. Roma: Aracne, 2005.

NYSVEEN, H.; THORBJORSEN, H.; PEDERSEN, P. Web TV channel additions. The International Journal on Media Management, n.7, 2004a. p.40-65.

NYSVEEN, H.; THORBJORSEN, H.; PEDERSEN, P. (2004b). Comparative advantages for broadcast companies. Disponivel em: herbjorn.nysveen@nhh. no. Acesso: 23 fev. 2012.

NOTARNICOLA A.; STEIBACH F. E l'azienda fa TV. Milano: Franco Angeli, 1997.

TE'EN, D. Review: a cognitive-affective model of organizational communication. MIS Quaterly, n.2, 2001.p. 18-32. 


\title{
Mídia, Ecologia e Sociedade
}

Contém textos de pesquisadores de diversos países, principalmente ibero-americanos, oferecendo um inventário crítico da diversidade e pluralidade da cultura brasileira e também das potencialidades dos meios de comunicação de massa. É discutido o ambientalismo brasileiro com importantes estudos e pesquisas desenvolvidas em escolas de Comunicação do país, resgatando as peculiaridades regionais juntamente com as problemáticas sócio-midiáticas.

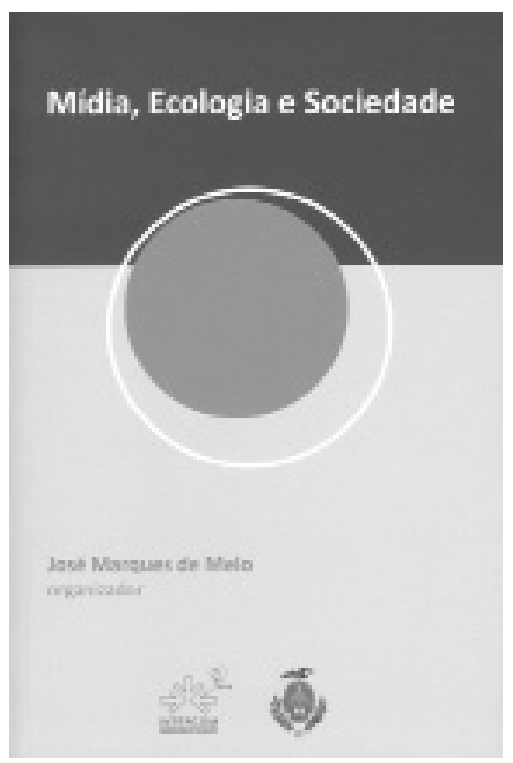

\author{
FAÇA SEU PEDIDO \\ pelo telefone (0xx11) 2574-8477, \\ e-mail: intercom@usp.br \\ ou acesse a Livraria Virtual da Intercom: \\ http://www.intercom.org.br
}

